\title{
Risk management in the construction industry: a new literature review
}

\author{
Berenger Y. Renault ${ }^{1, a}$ and Justus N. Agumba ${ }^{2}$ \\ ${ }^{1}$ University of Johannesburg, Johannesburg, South Africa \\ ${ }^{2}$ University of Johannesburg, Johannesburg, South Africa
}

\begin{abstract}
The construction industry is well known as a highly risk prone industry owing to the complexity of its activities and dynamic project environments generating an atmosphere of risks that must be taken into consideration in the decision process. For this reason, we have developed this treatise to elucidate the fundamentals of risk management through a concise new proposal of literature review for risk management in construction. Our explanation of this is venture is that over the years, this area has been acknowledged as a crucial process in the business institutions and the most discussed subject among experts and researchers in the construction sector. We have tried in this report to present the most recent studies considering the impossibility to present all definitions of the concept of risk. This study is mainly a literature review; it looks at the literature relating to the concept of risk, risk management in construction as well as methods used in construction industry.
\end{abstract}

\section{Introduction}

All human ventures bring in uncertainty and risk. It is agreed that risk is extreme in the business sector than other sectors. Every entrepreneurial act and a business decision are associated with risk. The risk is an occurrence that has a degree of obscurity and can either be positive or negative. A positive risk is a convenient opportunity, while a negative risk is a threat and hence inconvenient [1]. The more convenient and less convenient risks imply progressive and negative outcomes respectively. However, the CI faces fewer random risks, but these may have adverse consequences for a time, for example, increase cost, time overruns and low-quality work. The factors leading to such an outcome include planning, design and construction intricacy as well as the presence of countless interest groups and material resources [2]. Concerning risk negative impacts, [3] clarified that individuals dislike risk and that each party in the CI is risk averse; consequently, RM becomes significant in eliminating or reducing risk through the various processes of RM. [4] stated that RM has various complicated dimensions relating to the $\mathrm{CI}$, with results that go beyond its direct physical detriment to the financial and cultural processes, and even the way society functions. According to [5], all construction projects are hazardous by nature due to their configuration, financial and organizational arrangements, and technology and resource demands; hence, $\mathrm{RM}$ in construction projects is dynamic rather than stagnant. [6] argue that it is crucial for the industry to minimise these risks and uncertainties so as to unearth the impact thereof to determine which part of the project is more expose to risk and less feasible. RM has the task of identifying risks, measuring the

\footnotetext{
${ }^{1}$ Corresponding author: renault08@yahoo.fr
}

probability and the likely impact of events, and treating risks, eradicating or minimising their impact with the minimum investment of resources. $\mathrm{RM}$ is being developed and employed in a lot of fields, such as environment, public safety, within enterprise management, and health care. This paper focuses on RM in construction. [7], argued that RM when implemented, protects innovative projects, which are essential to gain competitive advantage and succeed in the market, but inevitably involve risky decisions and activities. Risk management could improve the ability to manage all stages of the innovative projects successfully. It has only been a few years since the management literature started to show an interest in applying RM in construction projects; for this reason, many areas are still understudied. This paper was developed to clarify the basics of risk management through a short new suggestion of literature review for risk management. The research objectives are therefore to analyze the existing literature concerning the concept of risk, RM and methods used in managing risks. The next section is devoted to the theoretical framework, including the definition of risk, risk management and risk management process.

\section{Literature review}

\subsection{Risks in construction}

The risk is attached to human life and is present in all human attempts. Nevertheless, the complexity of the work involved in construction activities makes the latter more predisposed to risk [8]. The part of the risk involved 
in construction is also more different and varies in degree owing to this complexity [9]. Several researchers have tried to define risk in various ways; generally these definitions were tailored to the objectives of the projects they were dealing with at a particular time. Nonetheless, the definition of risk is highly dependent on the importance placed on applied management in an establishment [10]. Risk describes a situation where former documentation and experience exist upon which measures are taken by obtaining a possible result [11]. Every time a decision is taken as a continuum of possible outcomes in addition to certain probabilities attached to the outcome, a risk exists [12]. Furthermore, [13] argue that risk is occasionally expansively defined, beyond financial, as a probability of loss, injury, setback, disadvantage or destruction. Similarly, [14] indicates that risk relates to a dearth of information or previous experience in a given situation being managed by a decision maker. Further, the risk is considered as the possibility of an investor's claim in construction work failing to achieve the predictable measures of feasibility [15]. All these authors proposed that risk was disagreeable occurrence; a consequence of imaginable but unexpected circumstances. Imaginable circumstances are events that announce their occurrence, whereas unexpected circumstances are events that occur without any notice.

Various definitions have divulged that risk has an impact or effect on any construction project. The effects thereof may be computed using many terms: financial loss; property damages; injury to people and even a combination of all of these [13]. [16] Indicates that project performance, quality, potency, capacity and financial cost could be altered if an element of risk is involved. According to [2], construction works such as planning, design and development are vulnerable to some factors in an uncertain environment. Construction projects are thus executed in an environment defined by a varying measure of risk and contingencies that could be from known or unknown conditions [12]. Such contingencies are chance occurrences of events where the probability distribution is unknown.

Risks, based on individual views can be categorised in different ways; some are classified based on their probability of occurring while others are classified as a consequence of the impact they may have on construction activities, their types and sources. Despite these various classifications, they are meant to attain a common objective, that is, they are an important aid in risk management and assist in forming risk lists that are used when detecting a risk [17] [18]. [18] furher indicated that that construction risks can be classified based not only on the impact of the risk on the project but also the source of the risk, while [19] stated that risks are mainly grouped into two categories according to their source, namely, internal and external. Risks comprise three groups: known risks, known unknown risks, and unknown risks [12]. The first category includes minimal variations and often occurs and is inevitable features of construction works. The second category is foreseeable risk events with a known probability of occurrence and impact. The last category is those which, the probability of occurrence cannot be predicted. According to [20], the risk could also be grouped based on sources concerned with stakeholders. For example, the time associated risks, environmentally associated risks, cost associated risks and safety associated risks. The sub-categories of human risks associated with construction projects include technical, political, social, economic, legal, financial, health, managerial and cultural risks. [21], grouped risk into ten categories, namely:

- Design: Defective design, inaccurate quantities, not coordinated design, rush design, awarding the design to unqualified designers, lack of consistency between bill of quantities, drawings and specifications

- Physical: Occurrence of accidents, because of poor safety procedures, supplies of defective materials, security of material and equipment, public security, varied labor and equipment productivity

- Logistics: Improper site investigation, inaccurate project program, unavailable labor, materials and equipment, high competition in bids, undefined scope of working, poor communications between the home and field offices (contractor side)

- Legal: Ambiguity of work legislations, difficulty to get permits delayed disputes resolutions, legal disputes during the construction phase among the parties to the contract, no specialized arbitrators to help settle fast

- Environmental: Adverse weather conditions, difficulty to access the site (very far), environmental factors (floods, earthquakes, etc.)

- Construction: Gaps between the implementation and the specifications due to a misunderstanding of drawings and specifications, actual quantities differ from the contract quantities, design changes, lower work quality in the presence of time constraints, rush bidding, undocumented change orders.

- Management: Poor communication between involved parties, ambiguous planning due to project complexity, changes in management ways information unavailability (include uncertainty), resource management

- Cultural: Religion, cultural custom

- Financial: Delayed payments on contract, unmanaged cash flow, inflation, financial failure of the contractor, exchange rate fluctuation, monopolizing of materials due to closure and other unexpected political conditions

- Political: New governmental acts or legislations, inflation, unstable security circumstances (invasions).

\subsection{Risk management in construction}

[8] Stipulates that managing risk makes a significant role in reducing the risks encountered in the CI as it provides a systematic way of assigning risk to construction 
projects, thus allowing projects to be managed with a higher degree of expectation and anticipation. According to [10], RM in the $\mathrm{CI}$ is the assessment and response to the risk that will be inevitably attached to a project. In parallel, RM is the approach and activities that are put in place to lessen the disturbances that may occur during the action of a project [22]. In essence, RM is required for the effective detection and proper control of risk. Effective risk management means any likely future occurrences thereof in a proactive manner [23]. Consequently, RM that attaches value to proactive measures puts in place an emergency plan that increases the probability of accomplishing the aims and objectives of the project [24]. [18] emphasises that RM involves increasing the results of positive occurrences and curtailing the effects of adverse events. In other words, $\mathrm{RM}$ is controlling occurrences that may result in a risk, instead of being passive before such occurrences and reacting later. All the measures that are put in place to control risk are geared towards achieving the project objectives. RM represents a major part of construction works. [11] Asserted that the requirement to manage risk in construction projects is incessantly increasing as a result of the complexity, size, competition, clientconsumer requirements, politico-economic challenges and major difficult physical conditions involved in such projects. Comprehensive RM will reduce the probability of an occurrence of an event just as it will reduce the extent of its impact. In accordance with [25], RM refers to a coordinated set of activities and methods that is used to direct an organization and to control the many risks that can affect its ability to achieve objectives. RM ensures that the decision-maker knows and understands the risks and prepares the necessary plan that can prevent disasters or diminish their impact. It covers the process of Identification, Assessment, Allocation, and Management of all project risks [26]. Risk management process (RMP) is the basic principle of understanding and managing risks in a project. All steps in the RMP should be included when dealing with risks, in order to efficiently implement the process in the project. It consists of the main phases [12] [28] [29] [30]:

\subsubsection{Risk identification (ID)}

This is the first stage in the RMP, and it involves capturing all potentials risk that might occur within the project [31]. Risk Identification (RI) forms the base for the next steps of risk analysis and control and enables organisations to learn about the areas that are exposed to risk. If appropriately performed, RI ensures successful risk management as unknown sources of losses escalate into unmanageable occurrences with unforeseen outcomes [32]. The emphasis is not only aimed at the incapability to identify loss causing risks but also includes the incapacity to determine opportunistic events. The effect of the non-identification of positive risks equates to the effect of non-identification of negative risks [32]. RI involves the identification of all possible risks and circumstances that may affect the organisation, as well as the conditions giving rise to these risks and opportunities. Risk identification, therefore, facilitates the efficient studying of areas and activities where organisational resources are at risk, affecting their ability to achieve their business goals [32]. To conduct RI efficiently, primary project documentation must be in place. The project charter, scope statement, and project management plan (Including the Work Breakdown Structure) need to be available to build an exhaustive list of risks. Without these elements as a frame of reference, it is difficult to assess the risks on a project effectively. The RM plan and the organizational atmosphere also must be undoubtedly understood to carry out RI. These form the environment in which the risks will be evaluated. The RM plan may also identify specific RI practices that are either favoured or banned by the organization as part of their risk culture. According to [33], all this information can encourage thinking about different risk matters and concerns when evaluated using the tools and techniques of RI. The tools and technology that are employed in RI are as varied as the projects they serve. Nevertheless, some groups of tool and technique types are most frequently used. The best known are Brainstorming, Interviews, Questionnaires, Delphi technique, Expert systems, etc.

\subsubsection{Risk assessment/analysis}

Risk identification follows on risk assessment. [34] [35] identified risk assessment as the next step of the risk management process. According to [8], risk assessment is a method of using available information to determine the frequency of occurrence and the level of consequences in risk management. According to [36], after all, the risks in a project have been identified; the process of qualitative risk assessment must follow which requires further analysis through assessing and estimating the probability of risk occurrence as well as its impact on each risk. Here, different factors need to be considered such as the degree of risk impact on project objectives and its manageability, the timing of an occurrence, and the likelihood of an occurrence and its relationship with other risks. All these factors provide a better understanding of each risk and allow room for a proper and appropriate way of responding to each risk. Two methods are developed for analyzing risk: qualitative and quantitative methods [31] [38]. The qualitative methods are most applicable when risks can be placed somewhere on a descriptive scale from low to high level. The quantitative methods on the other hand are employed to determine the probability and impacts of the risks identified and are based on statistics, arithmetic's estimations [39]. The table below summarises the various techniques used for risk analysis; all these technique are used in construction.

Table 1. Various risk analysis techniques (Ward \& Chapman, 1997)

\begin{tabular}{|l|l|}
\hline \multicolumn{2}{|c|}{ Risk Analysis } \\
\hline Qualitative & Quantitative \\
\hline Direct judgment & Probability analysis \\
\hline Ranking options & Sensitivity analysis \\
\hline
\end{tabular}




\begin{tabular}{|l|l|}
\hline Comparing options & Scenario analysis \\
\hline Descriptive analysis & Simulation analysis \\
\hline
\end{tabular}

\subsubsection{Risk responses (RRs)}

Risk response is a central component in the RMP that determines what action (if any) will be taken to address risks evaluated in the identification, qualification, and quantification stages [31]. According to [8], RRs are actions taken to eliminate, reduce or transfer a risk or its consequence. The risk response process encompasses planning for an obligatory action to be considered in case a risk event occurs. It also entails taking planned action if required and following up with the consequences of these actions to ensure that the risk plan results in the required outcome. A risk response is determined by proposing several alternatives to eliminate or mitigate an anticipated risk and assign an optimum alternative as a response [41]. According to [42], RR is the "process of identifying/developing risk response options and determining actions for treating the risk, targeting enhancing opportunities and reducing any threats to projects objectives". RR is, thus, the selection of an appropriate policy to decrease the negative impact of a risk. Given the fact that construction projects are distinctive, the risks involved are massive and dynamic in nature. Hence, it is indispensable to invent appropriate responses to these risks after the initial stages of risk identification, assessment and allocation. [43] defined RR as the planned documents procedure for RM that is used to manage risk throughout the project. It is the stage that involves taking proper measures to accomplish project objectives. Some studies recommend varied response techniques concerning risks in projects. [44] [45], argued that there four distinct ways of responding to risks in a construction project namely: risk avoidance, reduction, transfer and risk retention, whereas [12] divided the response techniques into three by combining avoidance and reduction. [43] on the other hand, indicated that risk responses can be grouped into mitigation or avoidance and acceptance.

\subsubsection{Risk control}

After risks have been identified, assessed, and appropriate responses have been developed, those findings must be put into action. Risk monitoring and control include implementing the risk plan, which should be an integral part of the project plan. Two key challenges are usually encountered during monitoring and controlling; the first is putting the risk plans into action and ensuring that they are still effective. The second is producing significant documentation to support the process. The step in the description of the RM flow adopted in this study includes ensuring the use of the previous steps. This is to ensure that the identified risks, which are regarded as important, are also controlled exactly the way it was organised in the response step.

In the control step, it is also possible to identify new risks that emerge and the continuous process proceeds According to [46] risk control aims at controlling deviations, minimise risks and increase the project value. This stage of the RMP handles risks in a way that project objectives are achieved effectively. Risk control is based on a proactive approach other than a reactive approach to having the right measures in place and refining on them continually. No ready-made solutions are available to minimise risks. However the following corrective measures can assist in handling the risks associated with construction projects [47] [36]:

- Adjust plans the scope of work and estimates to counter risk implications.

- Monitor risks regularly, evolve alternate plans to manage predictable risks, when needed.

- Make appropriate decisions.

- Keep all concerned informed about possible risks.

\section{Methodology}

The work methodology included a literature search. The research was conducted with reference to existing theoretical literature, published and unpublished literature. This research is mainly a literature review and looks at the literature relating to risk identification in the construction industry. This is because the concepts of risk and risk management have been on agenda for many years. To ascertain the aim of the study literature on risk management was embarked which considered subtitles including; definition of risk, concept of risk management and methods employed in identifying and analysing risks in constructions.

\section{Lessons learned from literature review}

This study has revealed that risk management implicates identifying, assessing and prioritizing risks by monitoring, controlling, and applying managerial resources with a coordinated and economic effort so as to reduce the likelihood of adverse events and so as to maximize the achievement of project objectives. Management risks may lead to several benefits such as identification of favorable alternative course of action, increased confidence in realizing project objective, improved chances of success, reduced surprises, more precise estimates, reduced duplication of effort. In additional, the reviewed literature also stressed that the entire risk management process is not only limited to with solving problem in advance but also for the occurrence of any unexpected future problems. The study further shown that issues with possible threats envisaged in a project are not only a means to reduce losses within the project, but also, a means to transfer risks into opportunities, which can lead to economic profitability, environmental and other advantages as postulated by [48]. Undoubtedly, this study has as well shown that compiling of a list of risks necessary for a particular project is a prudent and proactive activity to be embarked by a project team. This implies that if risk attached to a project is not firstly identified it will be almost impossible to respond to it thereby affecting the entire project. RM, as revealed by the study, must not be a 
standalone process rather a coordinated and integrated task that should involve all the project team to enable a successful risk management. Also, not all risks on projects are entirely of negative influence; some are an opportunity to explore into other segments of that would create profitability to the firm.

\section{Conclusion}

While most studies have focused on some aspects of project management, this paper has examined literature relating to risk management with the accomplishment of all project objectives regarding cost, time, quality, environment and safety. To achieve the objective of this study, the concepts of risk, RM and methods used in analyzing/assessing risk were reviewed. The literature showed that risk identification, risk analysis and assessment, risk response and control are crucial phases in risk management process. Risks must first be identified before they can be controlled or mitigated. Accordingly, this study concludes that risk management should be considered as the most significant activity for successful completion of a project. Risk identification techniques as concluded from this study includes the following: brainstorming, interviews/expert opinion, questionnaires, Delphi technique, expert systems, checklists and documentation review. In the analysis of risk, two categories of methods are developed: qualitative and quantitative methods. Literature revealed risk avoidance, risk reduction, risk transfer and risk retention as techniques mostly used in responding to risk. The study further concludes that issues with possible threats envisaged in a project are not only a means to reduce losses within the project, but also, a means to transfer risks into opportunities, which can lead to economic profitability.

\section{References}

1. Johnson, T. (2008). Project Management Professional (PMP) exam success series: certification exam mannual. Texas: Crosswind Project Management Inc

2. Creedy, G.D. (2005). Risk factors leading to cost overrun in the delivery of highway construction projects. $\mathrm{PhD}$ thesis, Queensland University of Technology, Australia

3. Laryea, S. (2008). Risk pricing practices in finances, insurance and construction. In: COBRA Research Conference, September 4th - 5th, Dublin Institute of Technology

4. Loosemore, M., Raftery, J., Reily, C. \& Higgion, D. (2006). Risk management in projects. London: Routledge

5. Edwards, P.J. \& Bowen, P.A. (2005). Risk and risk management in construction: a review and future direction for research, engineering, Construction and architectural management, 5(4): 339-349.

6. Zayed, T. Amer, M. \& Pan, J. (2007). Assessing risk and uncertainty inherent in Chinese highway project using AHP, International journal of project management, 26: 408-419

7. Vargas-Hernández, J.G. (2011). Modeling Risk and Innovation Management. Advances in Competitiveness Research, 19 (3-4), 45-57.

8. Olamiwale, I.O. (2014). Evaluation of Risk Management Practices in the Construction Industry in Swaziland. Master of Quantity Surveying Thesis, Tshwane University of Technology, Pretoria, South Africa.

9. Dey, P.K. \& Ogunlana, S.O. (2004). Selection and application of risk management tools and technique for build-operate-transfer-projects, Industrial management and data system, 4: 334-336.

10. Simu, K. (2006). Risk management in small construction projects. Licentiate dissertation. Department of Civil and Environmental Engineering, Lulea. LTU

11. Oztas, A. \& Okmen, O. (2004). Risk analysis in fixed price design-build construction projects, built and environment, 39, 229-237.

12. Smith, N.J., Merna, T., \& Jobbling P. (2006). Managing Risk in Construction Projects. 2nd edition Oxford: Blackwell Publishing

13. Abassi, G. Y., Abdel-Jaber, M. S. \& Abu-Khajedart, A. (2005). Risk analysis for the major factors affecting the construction industry in Jordan, Emirate, Journal of engineering research, 10: 41-47.

14. Al-Salman, A. (2004). Assessment of risk management perception and practices of construction contractors in Saudi Arabia. Master of Science, Fahd University of Petroleum \& Minerals.

15. Warszawski, A., \& Sacks, R. (2004). Practical Multifactor Approach to Evaluating Risk of Investment in Engineering Projects, Journal of Construction Engineering and Management, 130(3),357-367

16. Mills, A. (2001). A systematic approach to risk management for construction. Structural survey, 19(5): 245-252.

17. Wong, J.T.Y. \& Huie, E.C.M. (2006). Construction project risks: further considerations for contractors' pricing in Hong Kong. Construction management and economics, 24: $425-438$.

18. Klemetti, A. (2006). Risk management in construction project networks. Laboratory of Industrial Management, Helsinki University of Technology.

19. El-KarimiAzari, A., Mousavi, N., Mousavi, F.S., \& Hosseini, S. (2011). Risk Assessment model selection in Construction Industry. Iran University of Science and Technology, Islamic Azad University and Tarbiyat Modares University, Tehran, Iran.

20. Zou, P.X.W., Zhang, G. \& Wang, J. (2007). Understanding the key risks in construction projects in China. International journal of projets management, 25: 601- 614.

21. Kishan, P., Bhavsar, J.J., \& Bhatt, R. (2014). A Study of Risk Factors Affecting Building Construction Projects, International Journal of Engineering Research \& Technology, 3(12), 831-835 
22. Skorupka, D. (2008). Identification and initial risk assessment of construction projects in Poland. Journal of management in engineering, 24(3): 120127.

23. Kerzner, H. (1998). Project management: a system approach to planning, scheduling and control. New York, Chi Chester: Johnwill.

24. Adnan, H. (2008a). An Assessment of Risk Management in joint venture projects (JV) in Malaysia, Asian Social Science, 4(6),99-106.

25. AS/NZS ISO 31000: 2009 Risk ManagementPrinciples and Guidance. Retrieved from http://www.finance.gov.au/sites/default/files/COV_2 16905 Risk Management Fact Sheet FA3 230820 10 0.pdf.Accessed:16/01/2016.

26. Association for Project Management. (2000). Project Management Body of Knowledge, 4th edition, Project Risk Analysis and Management, a guide by APM.

27. Tuncel, G., \& Alpan, G. (2010). Risk assessment and management for supply chain networks: A case study, Computers in Industry, (61), 250-259

28. Giannakis, M., \& Louis, M.(2011). A Multi-agent based frame work for supply chain risk management, Journal of Purchasing and Supply Management, (17), 23-31

29. Mazouni, M.H. (2008). Pour une Meilleure Approche du Management des Risques : De la Modélisation Ontologique du Processus Accidentel au Système Interactif d'Aide à la Décision, Thèse de Doctorat de l'Institut National Polytechnique de Lorraine, Université de Nancy, France.

30. Ubani, Chinenye, E., Amade, Benedict, Okorocha, Aku, K., Agwu, A., \& Okogbuo,F.(2015). Project Risk Management Issues in the Nigerian Construction Industry, International Journal of Engineering and Technical Research, 3(1): 217-232.

31. Tchankova, L. (2002). Risk identification: basic stage in risk management. Environmental Management and Health, 13(3):290-297. Towers Perrin. 2008. Towers Perrin Risk and Opportunity WhitePaper.Availablefrom: http://www.towersperrin.com[Accessed 05/01/2016].

32. Kuang, Z. (2011). Risk Management in Construction Projects: Application of Risk Management in Construction Period. Bachelor of Architectural Technology and Construction Management. Via University College, Horsens Campus, Denmark.

33. DEAT (2006) Risk Management, Integrated Environmental Management Information Series 23, Department of Environmental Affairs and Tourism (DEAT),Pretoria-SouthAfrica. http://www.deat.gov.za. Accessed [03/01/2016]

34. Cooper, D., Grey, S., Raymond, G. \& Walker, P. (2005). Managing risks in large projects and complex procurement. Chichester: John Wiley.

35. Nguyen, N. P. \& Li, Y. (2012). "Critical analysis of risk management and significant impacts of its application on Sichuan Post-earthquakes Reconstruction project". Master of Science Thesis. Umea University, Sweden
36. Schatteman, D., Herroelean, W., Vandvonder, S. \& Boone, A. (2008). Methodology for integrated risk management and proactive scheduling of construction projects, Journal of construction engineering and management, 134(1): 885-893.

37. Winch, G., (2002). "Managing construction projects, an information processing approach". Oxford: Blackwell Publishing.

38. Chapman C. \& Ward S. (1997). "Project Risk Management: Processes, Techniques and Insights"

39. El-Dash, K. (2008). Construction risk management application and education selected. Proceeding from the $12^{\text {th }}$ International Congress on Project Engineering, 390-403.

40. Opolot, P.K., Buys, N.S. \& Slabber, J.M. 2009. Risk management in the South African construction industry.Availablefrom: http://www.yumpu.com/document/view/11842795/ri sk-management-in-the-south-africaconstruction. industry.html. Accessed: 10/01/2016

41. Lisa Turnbough, P.E. (2005). Risk management on large capital projects. Journal of professional issues in engineering and practices, 365-374.

42. Wang, M. \& Chou, H. (2003). Risk allocation and risk handling of highway projects in Taiwan. Journal of management in engineering, 19(22): 60-68.

43. PMI. (2008). A Guide to the Project Management Body of Knowledge. Project Management Institute, Newtown Square, PA.

44. Zenghua, K. (2011). Risk Management in Construction Projects. VIA University College, Horsens Campus, Denmark.

45. Dada, J.O. (2010) Strategies for militating risk in construction projects. In proceedings of the 40th Annual general meeting/conference of the Nigerian Institute of Building, 7th- 11th July 2010, Asaba, Delta, Nigeria, 28-35.

46. Lester, A., (2007). Project management, planning and control, 5th edition. Oxford: Elsevier Ltd Light Press. 